\title{
Prediction of Body Lipid Change in Pregnancy and Lactation
}

\author{
N. C. Friggens, ${ }^{1}$ K. L. Ingvartsen, ${ }^{1}$ and G. C. Emmans ${ }^{2}$ \\ ${ }^{1}$ Danish Institute of Agricultural Sciences, Department of Animal Health and Welfare, \\ Research Center Foulum, PO Box 50, DK-8830 Tjele, Denmark \\ ${ }^{2}$ Animal Biology Division, Scottish Agricultural College, \\ West Mains Road, Edinburgh EH9 3JG, UK
}

\section{ABSTRACT}

A simple method to predict the genetically driven pattern of body lipid change through pregnancy and lactation in dairy cattle is proposed. The rationale and evidence for genetically driven body lipid change have their basis in evolutionary considerations and in the homeorhetic changes in lipid metabolism through the reproductive cycle. The inputs required to predict body lipid change are body lipid mass at calving $(\mathrm{kg})$ and the date of conception (days in milk). Body lipid mass can be derived from body condition score and live weight. A key assumption is that there is a linear rate of change of the rate of body lipid change $(\mathrm{dL} / \mathrm{dt})$ between calving and a genetically determined time in lactation $\left(\mathrm{T}^{\prime}\right)$ at which a particular level of body lipid ( $\left.\mathrm{L}^{\prime}\right)$ is sought. A second assumption is that there is a linear rate of change of the rate of body lipid change $(\mathrm{dL} / \mathrm{dt})$ between $\mathrm{T}^{\prime}$ and the next calving. The resulting model was evaluated using 2 sets of data. The first was from Holstein cows with 3 different levels of body fatness at calving. The second was from Jersey cows in first, second, and third parity. The model was found to reproduce the observed patterns of change in body lipid reserves through lactation in both data sets. The average error of prediction was low, less than the variation normally associated with the recording of condition score, and was similar for the 2 data sets. When the model was applied using the initially suggested parameter values derived from the literature the average error of prediction was 0.185 units of condition score $( \pm 0.086 \mathrm{SD})$. After minor adjustments to the parameter values, the average error of prediction was 0.118 units of condition score ( $\pm 0.070 \mathrm{SD})$. The assumptions on which the model is based were sufficient to predict the changes in body lipid of both Holstein and Jersey cows under different nutritional conditions and parities. Thus, the model presented here shows that it is possible to predict genet-

Received July 17, 2003.

Accepted August 18, 2003.

Corresponding author: N. C. Friggens; e-mail: n.friggens@ agrsci.dk. ically driven curves of body lipid change through lactation in a simple way that requires few parameters and inputs that can be derived in practice. It is expected that prediction of the cow's energy requirements can be substantially improved, particularly in early lactation, by incorporating a genetically driven body energy mobilization.

(Key words: lactation, adipose, body condition score, genotype)

Abbreviation key: $\mathbf{M E}=$ metabolizable energy .

\section{INTRODUCTION}

Cows generally mobilize body lipid reserves in early lactation and regain these reserves during subsequent pregnancy. Lipid mobilized from body reserves makes a substantial contribution to the energetic cost of milk production in early lactation. It is frequently assumed that this mobilization of body energy reserves is entirely a response to a shortfall in food energy intake relative to milk energy output. This implies that increasing the energy content of the food being offered would decrease body energy mobilization in early lactation. There are a number of studies that indicate that this is not always the case (e.g., Gagliostro and Chilliard, 1991b; Grummer et al., 1995).

The view taken here is that both the mobilization of body reserves in early lactation, and the subsequent gain in body reserves during pregnancy, are to a large extent genetically driven. Seen in this way, body energy mobilization is not a response but rather a natural component of the reproductive cycle. It would be expected to be independent of food energy content. As shown in Figure 1, ignoring this preprogrammed body mobilization has important consequences for the prediction of energy requirements and the intake necessary to meet these requirements. With very few exceptions, current methods to predict energy requirements are based on estimates of milk production and maintenance. They do not explicitly allow for any genetically driven body energy mobilization. Prediction of the cow's energy requirements can be substantially improved, particularly 


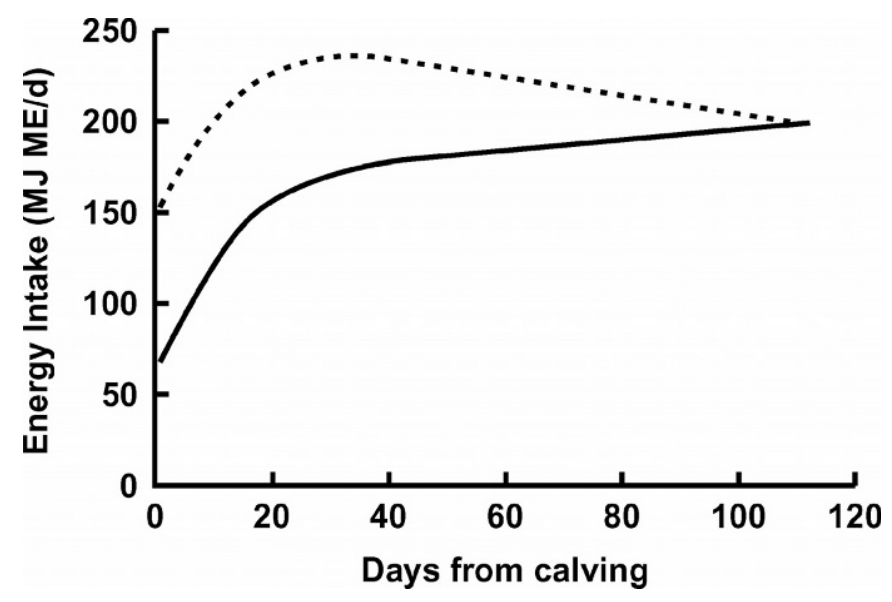

Figure 1. The effect of mobilization of body reserves on the energy intake needed to meet requirements for milk and maintenance in early lactation. The solid line is for a cow that loses $100 \mathrm{~kg}$ of body lipid between calving and $112 \mathrm{~d}$ postcalving. The dashed line is for a cow assumed to not lose (or gain) body lipid. In both cases, the cow was assumed to be yielding $6500 \mathrm{~kg}$ in $305 \mathrm{~d}$ and weigh $615 \mathrm{~kg}$ at $112 \mathrm{~d}$ postcalving. The energy intake was calculated from the energy requirements for milk production, maintenance, and body lipid change using the method of Emmans (1994) with the extension described by Coffey et al. (2001).

in early lactation, by incorporating genetically driven body energy mobilization.

The aims of this paper are: to provide the rationale for distinguishing between genetically driven and environmentally driven body lipid mobilization, and to present a method to quantify the genetically driven rate of change of body lipid at any given time-point in lactation.

\section{RATIONALE}

For clarity, it is important to define the terms "genetically driven" and "environmentally driven" in relation to body lipid change. Genetically driven body lipid change is defined as that which would occur in cows kept in an environment that was in no way constraining. It then follows that environmentally driven body lipid change is defined as that which occurs in response to an environment that is constraining.

The existence of environmentally driven body lipid mobilization, where mobilization is a response, is not in doubt. There are numerous examples showing that reduction in nutrient availability, caused by a decrease in the supply or quality of the food being offered, results in an increase in mobilization of body lipid (e.g., Friggens et al., 1998). The ability to buffer the consequences of a constraining nutritional environment is an important function of the body reserves. However, the existence of environmentally driven mobilization of the body reserves does not preclude the existence also of a genetically driven body mobilization. The existence of genetically driven body lipid mobilization is less well accepted, especially in relation to the postpartum period. It can be inferred from consideration of the evolutionary benefits of safeguarding reproductive success by strategic use of body reserves (Pond, 1984; Knight, 2001; Friggens, 2003).

The genetically driven accumulation of body reserves by the mother during pregnancy to support the energetic demands of the following lactation confers obvious advantages (Vernon and Pond, 1997; Oftedal, 2000). However, it is not so obvious that there should be a genetically driven loss of body lipid in early lactation. If the environmental pressure to mobilize body lipid in early lactation were removed, for instance by provision of super-abundant nutrition, why should the mother still mobilize? There are evolutionary arguments as to why it would be advantageous to decrease the size of the body reserves with increasing time from birth (Friggens, 2003) that are related to the cost of having body reserves. Carrying additional body mass increases the energy costs of movement. The reduction in mobility that results will, in a natural environment, increase the risk of predation in predated species and the risk of failing to predate successfully in predators.

The extent to which these arguments are of major relevance to domestic livestock such as dairy cattle is open to question. Experimental studies may offer more direct evidence, particularly those that have sought to modulate body reserves and rates of mobilization. The evolutionary arguments alluded to above imply that at any given time in pregnancy and lactation there is an optimal level of body fatness that the animal is genetically driven to attain. There is thus a trajectory or pattern of body fatness through the reproductive cycle. The notion of genetically determined trajectories in development of body tissues, including fat, has long been accepted in the study of growth (Hammond, 1940; Waddington, 1957; Emmans, 1988). An important feature of such trajectories is that they are defended, and that deviations from the trajectory are generally followed by compensatory or corrective adjustments to regain the trajectory once environmental conditions allow (Allden, 1970; Wright and Russel, 1991).

It is commonly found that dairy cows become increasingly fat as they progress through pregnancy (e.g., Koenen et al., 2001). However, at the same time milk yield is usually declining and it is usually only in the last 2 mo of pregnancy that the cow is not concurrently lactating. This makes it difficult to attribute the change in body fatness solely to the degree of pregnancy, and a definitive study in dairy cattle is lacking (Knight, 2001). There is, however, some evidence that the trajectory of body fatness through pregnancy, usually mea- 
sured as body condition score, is defended. A striking feature of multiple-lactation studies that involve underfeeding is that, although underfeeding causes substantially greater loss of body reserves in early lactation, there is generally little difference in condition score between underfed and control cows by the end of the subsequent pregnancy (Broster et al., 1993; Chilliard et al., 2000). When given favorable feeding, cows compensate for prior nutritional insult by rapidly regaining body condition (Friggens et al., 1998; Morrison et al., 1999). The same was found to apply to cows that had undergone a period of draught work (Zerbini et al., 1996).

There is also some evidence of cows defending the trajectory relative to overfeeding of energy. We have previously fed lactating cows and nonlactating heifers, with the same starting condition score, either a high or a normal energy density diet during the last $24 \mathrm{wk}$ of gestation (Ingvartsen et al., 1995). The cows responded to the overfeeding by diverting almost all the increased energy into milk and appeared to defend their genetically driven level of body fatness. Only when the option of diverting energy into milk was not available, i.e., in the heifers, did the energy overfeeding distort the genetically determined trajectory of body fatness.

It thus appears that the drive to attain the genetically determined trajectory of body fatness through pregnancy is accorded a high priority. A possible mechanism is suggested by the available literature on the changes that occur in the metabolism and endocrine sensitivity of adipose tissue as pregnancy progresses. For most of pregnancy, the rate of lipogenesis is enhanced and the rate of lipolysis is relatively low, favoring lipid accretion (Vernon and Flint, 1984). As parturition approaches, these relative rates are reversed such that lipid mobilization is favored (Vernon and Flint, 1984; Vernon et al., 2001). A number of hormones have been implicated in the control of adipose metabolism in pregnancy, in particular insulin, and changes in insulin sensitivity of adipose tissue appear to be important (Vernon et al., 2001). More recently, a marked increase in expression of leptin mRNA by adipose tissue with advancing pregnancy has been reported in sheep (Ehrhardt et al., 2001).

The concerted changes in the endocrine milieu that start at the end of pregnancy continue in early lactation (McNamara, 1997). In relation to adipose tissue it is well documented that lipogenesis, especially reesterification of fatty acids, is heavily down-regulated and lipolysis is substantially increased in early lactation (McNamara, 1997; Chilliard et al., 2000). With respect to genetically driven trajectories of body mobilization, an important finding is that the responsiveness of adipose tissue to lipolytic stimuli (usually $\beta$-adrenergic agonists) is markedly enhanced in early lactation (Metz and van den Bergh, 1977; Theilgaard et al., 2002). Not only is this responsiveness affected by energy balance and body fatness, but there is a marked effect of physiological state (lactating vs. nonlactating) on lipolytic response (Chilliard et al., 1998; Theilgaard et al., 2002). Manipulation of key hormones in early lactation such as insulin, growth hormone, and leptin also cause marked changes in body energy mobilization (Ingvartsen and Boisclair, 2001).

There is strong evidence that the trajectories of body fatness through early lactation are strongly defended. It has been repeatedly shown that nutritional manipulation of cows to be fatter, or leaner, than normal at calving provokes a change in subsequent body lipid mobilization such that normal levels of body fatness are regained approximately 3 to 4 mo after calving (Garnsworthy and Topps, 1982; Broster and Broster, 1998). Further, in situations where very high levels of nutritional resources are provided, mobilization of body lipid reserves still occurs, even though there is no apparent need for the energy this provides (Friggens et al., 1993). In dairy cows, attempts to decrease lipid mobilization by supplementation with dietary lipid in early lactation have not been successful (Gagliostro and Chilliard, 1991a; Grummer et al., 1995). We have found no convincing evidence that cows, which have gained body lipid in pregnancy, retain these extra reserves in the subsequent lactation.

In summary, the available evidence from the literature is generally consistent with there being a genetically driven component to changes in body reserves through both pregnancy and lactation. It is therefore not surprising that there are strong genetic correlations between measures of body fatness at different timepoints in lactation (Coffey et al., 2001; Pryce et al., 2002). Genetically driven processes are, by their nature, amenable to description and therefore should be able to be incorporated into predictions of energy requirements. However, it is clear from the above considerations of trajectories that it is necessary to recognize 2 types of genetically driven body mobilization. As shown in Figure 2, a cow that is currently in a nonconstraining environment can be either following her genetically predetermined trajectory of body fatness or be in the process of reconverging on that trajectory, i.e., compensating for a previous nutritional insult.

Three types of body mobilization are postulated: environmentally driven, genetically driven predetermined, and genetically driven compensatory mobilization. They have a close analogy to the components of models used in the genetic evaluation of traits through time. In these models, the phenotypic curves are split into environmental effects and animal effects. The animal 


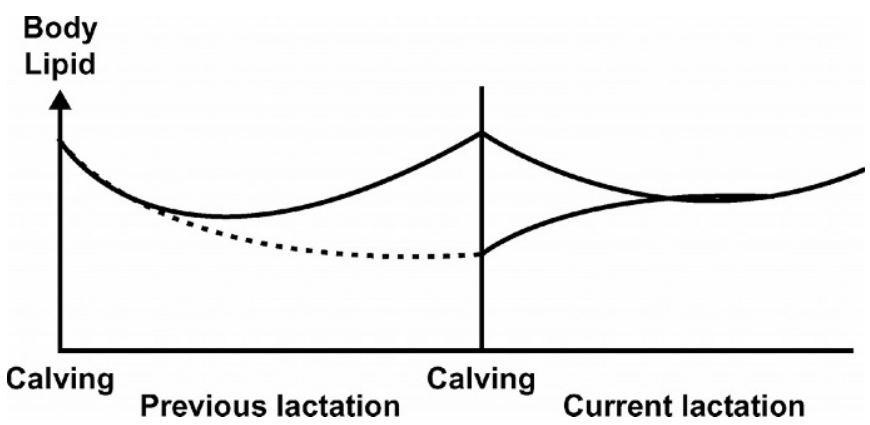

Figure 2. A schematic representation of the effect of prior environment on genetically driven body lipid change in the current lactation. A noncompromising environment (solid lines) in the previous lactation results in the genetically driven predetermined body lipid change in the current lactation. A compromised environment (dashed line) in the previous lactation results in a genetically driven compensatory body lipid change in the current lactation.

effects are usually further partitioned into a function describing the effect of genotype through time and one describing systematic, animal associated, deviations from the genotype function (e.g., Coffey et al., 2001). (In the context of biological explanations, this latter function has an unfortunate name as it is usually referred to as the permanent environmental effect. It is an environmental effect only in the sense that it is not directly attributable to the genetic structure [pedigree] and it is only permanent within the time frame being considered).

The method presented below for predicting genetically driven body lipid mobilization aims to describe the general biological framework for this process. Such a model would provide the basis for biologically meaningful genetic evaluation of genetically driven body lipid mobilization, though this is beyond the scope of the current paper.

\section{MODEL DESCRIPTION}

\section{Assumptions}

To construct a curve of genetically driven body lipid change over time, the following initial assumptions are made for a cow of a given size.

A1 The cow is driven to have a specific amount of lipid, here called L' $(\mathrm{kg})$, at a particular time in lactation, here called $\mathrm{T}^{\prime}$ (expressed as days from calving).

A2 The rate of change of body lipid, dL/dt $(\mathrm{kg} /$ d), itself changes linearly with time between calving and $\mathrm{T}^{\prime}$.

A3 If pregnant, the cow is driven to have a specific amount of lipid at the next calving, here called $\mathrm{L}_{\text {next }}(\mathrm{kg})$.

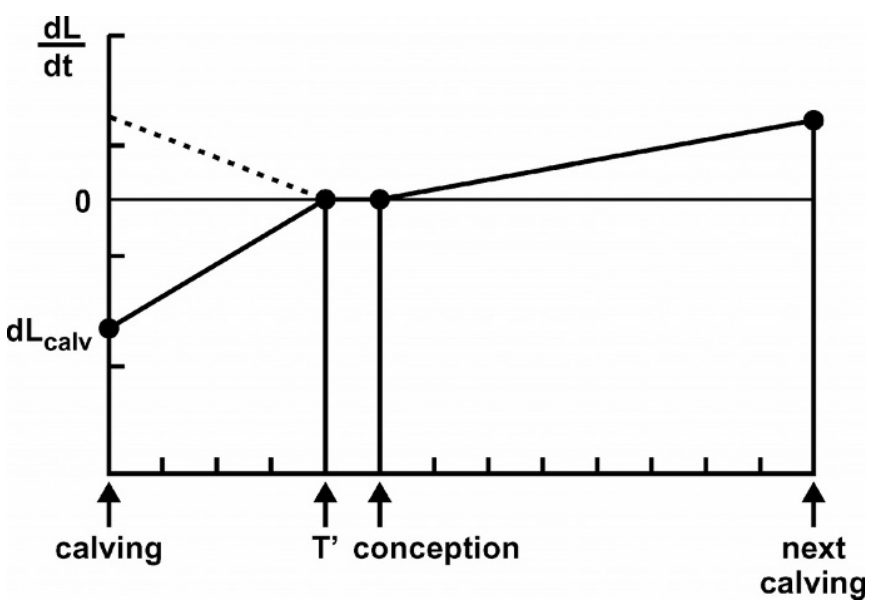

Figure 3. The rate of change of body lipid (dL/dt) relative to days from calving for 2 cows-one with adequate body lipid reserves at calving (solid line) and one with very little body lipid at calving (dashed line). $\mathrm{T}^{\prime}$ is the time at which $\mathrm{dL} / \mathrm{dt}$ is assumed to reach zero.

A4 The rate of change of body lipid (dL/dt) itself changes linearly with time between conception and the next calving.

A5 At times greater than $\mathrm{T}^{\prime}$, and if the cow is not pregnant then $\mathrm{dL} / \mathrm{dt}$ is assumed to be 0 , i.e., the cow has no drive to increase body lipid.

These assumptions, when combined with the appropriate inputs (described below), are sufficient to generate the curves shown in Figures 3 and 4 . The need for additional assumptions to deal with 2 particular cases becomes apparent when the following questions are considered.

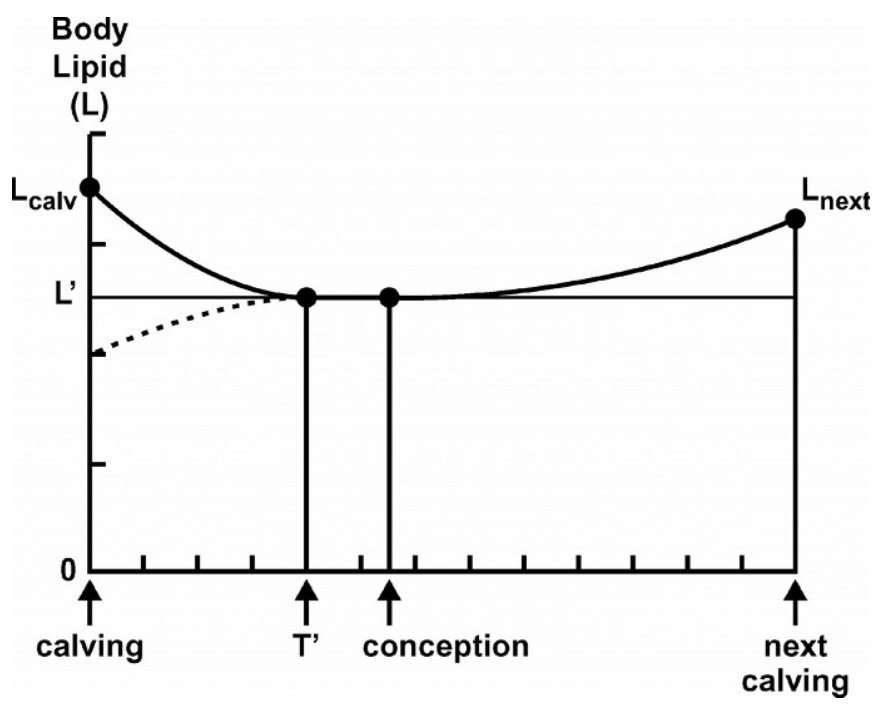

Figure 4. The amount of body lipid relative to days from calving for 2 cows-one with adequate body lipid reserves at calving (solid line) and one with very little body lipid at calving (dashed line). 


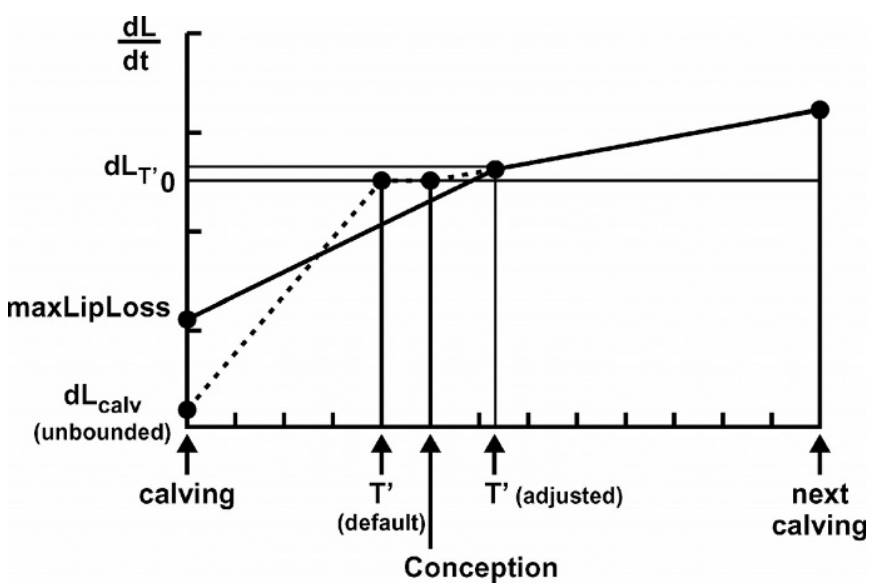

Figure 5. The effect of imposing a maximal rate of body lipid loss on the rate of change of body lipid $(\mathrm{dL} / \mathrm{dt})$ relative to days from calving. The reduction in the initial rate of lipid loss ( $\mathrm{dL}_{\text {calv }}$ unbounded) forces $\mathrm{T}^{\prime}$ to be increased to adjusted $\mathrm{T}^{\prime}$. Because adjusted $\mathrm{T}^{\prime}$ is now after conception, $\mathrm{dL} / \mathrm{dt}$ at adjusted $\mathrm{T}^{\prime}$ is not zero.

Is there a maximal allowable rate of lipid loss?

What happens if conception occurs before $\mathrm{T}^{\prime}$ ?

If no limit is put on the rate of lipid loss then, because $\mathrm{T}^{\prime}$ is fixed, cows that are relatively fat at calving can supply all of their energy needs from body reserves for some time. A consequence is that no food intake would be needed to meet the requirements of the cow. As resources other than energy will always be needed from the food this is an unreasonable result. To deal with this without expressly considering resources other than energy a further assumption is made.

A6 There is a maximal rate of lipid loss, called maxLipLoss $(\mathrm{kg} / \mathrm{d})$. This is a negative value of $\mathrm{dL} / \mathrm{dt}$.

When the initial rate of change of body lipid, $\mathrm{dL}_{\text {calv }}$, is calculated to be less than maxLipLoss, the cow cannot, given A6, meet both assumptions A1 and A2 unless provision is made for allowing either $\mathrm{L}^{\prime}$ or $\mathrm{T}^{\prime}$ to change. Relaxing the assumption that the change in the rate of lipid change was linear was considered but rejected. The solution adopted requires the following further assumption.

A7 $\quad \mathrm{T}^{\prime}$ can increase to allow $\mathrm{L}^{\prime}$ to be achieved without exceeding maxLipLoss.

The effect of this assumption is shown in Figure 5. The broken line shows the case in which no maximal lipid loss is imposed. The solid line shows what happens when assumptions A6 and A7 are applied. The exact value of $\mathrm{T}^{\prime}$ needed for $\mathrm{dL}_{\text {calv }}=$ maxLipLoss is obtained by replacing $\mathrm{dL}_{\text {calv }}$ with maxLipLoss in equation (1).

When $T^{\prime}$ is increased to accommodate very fat cows within the above rules for maxLipLoss, then it is possible for $\mathrm{T}^{\prime}$ to occur after conception. If no modification is made then there is a discontinuity between the rates of lipid change before and after $\mathrm{T}^{\prime}$. To prevent this happening 2 further assumptions are needed.

A8 When $T^{\prime}$ occurs after conception, the rate of body lipid change at $\mathrm{T}^{\prime}\left(\mathrm{dL}_{\mathrm{T}^{\prime}}\right)$ is the rate that the cow would ordinarily have had given her degree of pregnancy.

A9 A cow still losing body lipid after conception is driven to achieve not $\mathrm{L}^{\prime}$ but the level of body lipid that she would ordinarily have had given her stage of pregnancy, i.e., L' plus the pregnancy gain in lipid. This modified target amount of lipid is called $\mathrm{L}_{\text {target }}$.

\section{Equations and Inputs}

The model requires the following inputs: the amount of body lipid the cow has at calving $\left(\mathrm{L}_{\text {calv }}\right)$ and the time of conception (Con). $\mathrm{L}_{\text {calv }}$ can be derived from live weight and condition score at calving (see below). The model parameters are listed in Table 1.

The logic of the equations is relatively simple to follow in the case in which $\mathrm{T}^{\prime}$ occurs before conception but becomes less obvious in the case where $\mathrm{T}^{\prime}$ occurs after conception. Therefore, for clarity, the equations are presented for the 2 cases separately even though they can be combined into one equation set which deals with both cases.

The case in which $T^{\prime}$ occurs before conception. Based on assumptions $\mathrm{A} 1$ and $\mathrm{A} 2$, the initial rate of lipid mobilization, $\mathrm{dL}_{\text {calv }}$, is calculated on the basis that the total amount of lipid mobilized, the area of the triangle defined by coordinates (calving, 0$),\left(\mathrm{T}^{\prime}, 0\right)$, and (calving, $\mathrm{dL}_{\text {calv }}$ ) in Figure 3 , must be equal to $\mathrm{L}^{\prime}-$ $\mathrm{L}_{\text {calv. }}$ Therefore:

$$
\mathrm{dL}_{\text {calv }}=2\left(\mathrm{~L}^{\prime}-\mathrm{L}_{\text {calv }}\right) / \mathrm{T}^{\prime}
$$

If $\mathrm{dL}_{\text {calv }}$ is more negative than maxLipLoss (see A6) then the following adjustments are made according to A7:

$$
\begin{gathered}
\mathrm{dL}_{\text {calv }}=\text { maxLipLoss } \\
\mathrm{T}^{\prime}=2\left(\mathrm{~L}^{\prime}-\mathrm{L}_{\text {calv }}\right) / \text { maxLipLoss }
\end{gathered}
$$

At any time between calving and $\mathrm{T}^{\prime}$ the rate of lipid change $(\mathrm{dL} / \mathrm{dt})$ is given by:

$$
\mathrm{dL} / \mathrm{dt}=\mathrm{dL}_{\mathrm{calv}}\left(1-\left(\mathrm{DFCalv} / \mathrm{T}^{\prime}\right)\right)
$$

When $\mathrm{L}_{\text {calv }}=\mathrm{L}^{\prime}$ there is no change in lipid between calving and $T^{\prime}$. When $\mathrm{L}_{\text {calv }}$ is less than $\mathrm{L}^{\prime}$ body lipid increases between calving and $\mathrm{T}^{\prime}$. Similarly, using assumptions A3 and A4, the rate of change of body lipid between conception and next calving can be calculated 
Table 1. Parameter names used in the model to predict genetically driven body lipid change.

\begin{tabular}{lll}
\hline $\begin{array}{l}\text { Parameter } \\
\text { name }\end{array}$ & Units & Description \\
\hline Con & days & Time of conception in days from calving \\
DFCalv & days & Time from calving \\
DFCon & days & Time from conception \\
Gest & days & Length of gestation \\
$\mathrm{T}^{\prime}$ & days & Time at which the cow is driven to have lipid mass $\mathrm{L}^{\prime}$ in days from calving \\
$\mathrm{dL} / \mathrm{dt}$ & $\mathrm{kg} / \mathrm{d}$ & Rate of change of body lipid \\
$\mathrm{dL}_{\text {calv }}$ & $\mathrm{kg} / \mathrm{d}$ & Rate of change of body lipid at calving \\
$\mathrm{dL}_{\text {next }}$ & $\mathrm{kg} / \mathrm{d}$ & Rate of change of body lipid at the next calving \\
$\mathrm{dL} \mathrm{T}^{\prime}$ & $\mathrm{kg} / \mathrm{d}$ & Rate of change of body lipid at $\mathrm{T}^{\prime}$ \\
$\mathrm{MaxLipLoss}^{\prime}$ & $\mathrm{kg} / \mathrm{d}$ & Maximal rate of lipid loss \\
$\mathrm{L}^{\prime}$ & $\mathrm{kg}$ & Body lipid mass the cow is driven to have at time $\mathrm{T}^{\prime}$ \\
$\mathrm{L}_{\text {calv }}$ & $\mathrm{kg}$ & Body lipid mass at calving \\
$\mathrm{L}_{\text {next }}$ & $\mathrm{kg}$ & Body lipid mass the cow is driven to have at the next calving \\
$\mathrm{L}_{\text {target }}$ & $\mathrm{kg}$ & Body lipid mass the cow is driven to have at $\mathrm{T}^{\prime}$ when $\mathrm{T}^{\prime}$ occurs after conception \\
\hline
\end{tabular}

on the basis that the area of the triangle under the line after conception (Figure 3 ) must be equal to $L_{\text {next }}-L^{\prime}$. Therefore, between conception and next calving:

$$
\mathrm{dL}_{\text {next }}=2\left(\mathrm{~L}_{\text {next }}-\mathrm{L}^{\prime}\right) / \mathrm{Gest}
$$

where $d L_{\text {next }}$ is the rate of lipid change at the next calving and Gest is the length of pregnancy. At any time between conception and the next calving the rate of lipid change is given by:

$$
\mathrm{dL} / \mathrm{dt}=\left(\mathrm{dL}_{\text {next }} / \text { Gest }\right)(\text { DFCalv }- \text { Con })
$$

It follows that:

$$
\mathrm{dL} / \mathrm{dt}=2\left(\mathrm{~L}_{\text {next }}-\mathrm{L}^{\prime}\right)(\mathrm{DFCalv}-\mathrm{Con}) /\left(\mathrm{Gest}^{2}\right)
$$

The case in which $T^{\prime}$ occurs after conception. In this case, $L^{\prime}$ is no longer the target level of lipid that the cow is driven to achieve. Instead, the cow is "aiming" for $\mathrm{L}_{\text {target }}$ (A9), and the rate of body lipid change for that stage of pregnancy (A8). In other words, dL/dt at $\mathrm{T}^{\prime}$, here called $\mathrm{dL}_{\mathrm{T}^{\prime}}$, is not zero (Figure 5 ). Thus some adjustments to equation 1 are necessary, resulting in:

$$
\mathrm{dL}_{\text {calv }}+\mathrm{dL}_{\mathrm{T}^{\prime}}=2\left(\mathrm{~L}_{\text {target }}-\mathrm{L}_{\text {calv }}\right) / \mathrm{T}^{\prime}
$$

$\mathrm{L}_{\text {target }}$ and $\mathrm{dL}_{\mathrm{T}^{\prime}}$ can be derived from adjustments of the equations relating to the period from conception to next calving as follows:

$$
\begin{gathered}
\text { DFCon }=\mathrm{T}^{\prime}-\text { Con } \\
\mathrm{L}_{\text {target }}=\mathrm{L}^{\prime}+(\text { Lipid gain during DFCon })
\end{gathered}
$$

Lipid gain during DFCon is the area of the triangle between the line from conception to $\mathrm{T}^{\prime}$ and $\mathrm{dL} / \mathrm{dt}=0$ in Figure 5. Thus $\mathrm{L}_{\text {target }}$ is:

$$
\mathrm{L}_{\text {target }}=\mathrm{L}^{\prime}+\left(\mathrm{dL}_{\mathrm{T}^{*}} * \mathrm{DFCon}\right) / 2
$$

where the asterisk denotes the product of the 2 associated parameters.

The value of $\mathrm{dL}_{\mathrm{T}^{\prime}}$ is calculated from equation 7 with DFCon substituting for (DFCalv - Con), therefore:

$$
\mathrm{dL}_{\mathrm{T}^{\prime}}=2 * \mathrm{DFCon}\left(\mathrm{L}_{\text {next }}-\mathrm{L}^{\prime}\right) /\left(\mathrm{Gest}^{2}\right)
$$

Substituting equation 12 in equation 11 gives:

$$
\begin{gathered}
\mathrm{L}_{\text {target }}= \\
\mathrm{L}^{\prime}+\left(\left(2 * \mathrm{DFCon}\left(\mathrm{L}_{\text {next }}-\mathrm{L}^{\prime}\right) /\left(\mathrm{Gest}^{2}\right)\right) * \mathrm{DFCon}\right) / 2
\end{gathered}
$$

it follows that:

$$
\mathrm{L}_{\text {target }}=\mathrm{L}^{\prime}+\left(\mathrm{DFCon}^{2}\right)\left(\mathrm{L}_{\text {next }}-\mathrm{L}^{\prime}\right) /\left(\mathrm{Gest}^{2}\right)
$$

The equation for $\mathrm{dL}_{T^{\prime}}$ (12) contains only one unknown, $T^{\prime}$. The same is true for $\mathrm{L}_{\text {target }}$ (equation 14). Therefore, equation 8 appears to contain 2 unknowns- $\mathrm{dL}_{\text {calv }}$ and $\mathrm{T}^{\prime}$. However, given assumptions $\mathrm{A} 1, \mathrm{~A} 2, \mathrm{~A} 6$, and $\mathrm{A} 7$, only one of $\mathrm{dL}_{\text {calv }}$ and $\mathrm{T}^{\prime}$ can be unknown in any given situation. If $\mathrm{T}^{\prime}$ is not changed from the default value, then $\mathrm{dL}_{\text {calv }}$ is unknown. If $\mathrm{T}^{\prime}$ is unknown, i.e., it is changed from the default value, this is because $\mathrm{dL}_{\text {calv }}$ has been set to maxLipLoss and is thus known.

Equation 8 can now be solved for $\mathrm{dL}_{\text {calv }}$, assuming $\mathrm{T}^{\prime}$ is not changed from the default value. If the resulting value of $\mathrm{dL}_{\text {calv }}$ is less than maxLipLoss, then $\mathrm{dL}_{\text {calv }}$ should be set to maxLipLoss and equation 8 solved for $\mathrm{T}^{\prime}$. The relevant rates of body lipid change before and after $\mathrm{T}^{\prime}$ are then given by equations 4 and 7 .

\section{Estimation of Body Lipid Mass from Weight and Condition Score}

Body lipid mass, for example $\mathrm{L}_{\text {calv }}$, can be calculated as the product of empty BW and the proportion of lipid 
Table 2. Initial parameter values for the prediction of genetically driven body lipid change.

\begin{tabular}{llc}
\hline Model & & \\
parameter & Units & Value \\
\hline $\mathrm{T}^{\prime}$ & days from calving & 112 \\
$\mathrm{~L}^{1}$ & g lipid/g empty body & 0.26 \\
$\mathrm{~L}_{\text {next }} 1$ & g lipid/g empty body & 0.32 \\
maxLipLoss & kg lipid/day & -1.75 \\
Gest & days & 284 \\
\hline
\end{tabular}

${ }^{1}$ Because a number of different condition score scales exist and because lipid mass at a given condition score is a function of the size of animal (Zygoyiannis et al., 1997), the values for $L^{\prime}$, and $L_{\text {next }}$ are given here as proportions. A method for converting these proportions to kilograms of lipid is given in the model description.

in the empty body. These quantities can be estimated from live weight and BCS.

To convert BCS (measured on a 0 to 5 scale (Lowman et al., 1976)) to body lipid proportion, the following equation derived from the serial slaughter experiments of Wright and Russel (1984) on nonpregnant mature cows was used:

$$
\begin{gathered}
\text { Body lipid proportion }(\mathrm{g} / \mathrm{g} \text { of empty body })= \\
0.120(\text { Condition score }-0.36)
\end{gathered}
$$

Empty BW can be calculated from live weight if estimates of gut fill are available. In a given cow, it is not expected that gut fill increases with increasing body fatness. However, as condition score increases so does live weight. Thus, if gut fill is estimated as a function of live weight then that live weight should be standardized for condition score (e.g., Zygoyiannis et al., 1997). Standardized live weight and empty BW were derived by assuming that the live weight associated with a unit change in condition score was 0.129 (live weight at condition score 5) and that the gut fill was 0.15 of live weight at condition score 3 (Zygoyiannis et al., 1997).

\section{Parameter Values and Model Evaluation}

Initial values for the parameters in Table 2 were estimated from available studies, where it was judged that the trajectories of condition score change through lactation were largely unaffected by feeding and thus reflected genetically driven mobilization. Because a number of different condition score scales exist and because lipid mass at a given condition score is a function of the size of animal (Zygoyiannis et al., 1997), the values for $\mathrm{L}^{\prime}$, and $\mathrm{L}_{\text {next }}$ are given as proportions in Table 2 . Using the 0 to 5 condition score scale of Lowman et al. (1976), the value of $0.26 \mathrm{~g}$ of lipid/g of empty body for $L^{\prime}$ equates to condition score 2.5 and the value of $0.32 \mathrm{~g}$ lipid/g of empty body for $\mathrm{L}_{\text {next }}$ equates to condition score 3.0. For the purpose of model evaluation, the re- sults are not sensitive to the assumptions used for converting condition score and live weight to body lipid mass.

Two data sets were used for model evaluation; they were chosen as they provided a relatively diverse set of conditions. The first set was used to test the model with respect to the effect of body lipid reserves at calving, $\mathrm{L}_{\text {calv }}$, on the trajectories of body lipid in Holstein heifers in the first part of lactation. The second set was used to explore the effects of parity on the model parameters in Jersey cows.

For the first test, back fat thickness measured by ultrasound scanning and live weight data from 36 Danish Holstein heifers in the period from calving to $22 \mathrm{wk}$ postcalving were used. In the $24 \mathrm{wk}$ up to calving, the heifers were split into 3 groups receiving rations of high, medium, and low quality designed to result in different levels of body fatness at calving. After calving, all the heifers received the same adequate TMR (11.7 MJ of metabolizable energy/kg of DM) ad libitum. In a previous experiment under the same conditions, the ratio condition score:back fat thickness was found to be $0.25\left(\mathrm{R}^{2}=98 \%\right.$; Ingvartsen, unpublished). This was used to convert the ultrasound measurements to condition scores, which together with live weight values were used to calculate $\mathrm{L}_{\text {calv }}$. The average live weights at calving were 555, 604, and $650 \mathrm{~kg}$ for low, medium, and high groups, respectively. Conception occurred on average at 92 DIM.

In the second data set, condition score and live weight data from 65 Jersey cows were used. The data were collected within an experiment in which the cows received either a high or a low quality feed ad libitum throughout lactation. Data from the high quality feeding treatment only were used. (Data from the low quality feeding treatment were excluded as this treatment was designed to be nutritionally limiting and thus cause environmentally driven mobilization.) The data comprised 26 first, 23 second, and 16 third lactations. The average live weight at calving for first, second, and third parity was 403,443 , and 476 , respectively. The average DIM of conception of the first, second, and third parity cows was 106, 105, and 102, respectively. Further details of this experiment have been reported (Nielsen et al., 2003).

The ability of the model to fit the observed data was estimated using the error of prediction, which is the square root of the ratio between the mean square of the prediction error (MSPE) and the observed mean. The MSPE was defined as follows:

$$
\mathrm{MSPE}=\Sigma\left(\mathrm{O}_{\mathrm{i}}-\mathrm{P}_{\mathrm{i}}\right)^{2} / \mathrm{n}
$$

where $\mathrm{O}_{i}$ is the ith observed value, $\mathrm{P}_{\mathrm{i}}$ is the ith predicted value and $\mathrm{n}$ is the total number of observations. 
The error in central tendency (ECT), which provides a measure of the bias of the prediction, was also calculated as the square of the difference between the average of the predicted values and the average of the observed values. The ECT was used to calculate the percentage bias:

$$
\operatorname{bias}(\%)=100 * \mathrm{ECT} / \mathrm{MSPE}
$$

\section{RESULTS}

The comparison between predicted and observed condition score values for the Holstein data set with 3 levels of body condition at calving is shown in Figure 6 . The model provided a satisfactory fit to the observed data. The average error of prediction was 0.225 units of condition score (Table 3); this compares favorably with the variation in the observed data. However, as can be seen from Figure 6, using the parameter set given in Table 2 resulted in a consistent under-prediction of the nadir in condition score, with bias accounting for more than $70 \%$ of the error of prediction (Table 3 ). Adjusting the value of $L^{\prime}$ from 0.26 to 0.29 (for consistency, $\mathrm{L}_{\text {next }}$ was also adjusted from 0.32 to 0.35 ) resulted in a significantly better fit (Figure 6) with the error of prediction being, on average, halved (Table 3). This adjustment represents an increase of approximately $0.25 \mathrm{U}$ of condition score for $\mathrm{L}^{\prime}$ and $\mathrm{L}_{\text {next }}$. A quarter condition score is well within the reported between observer variation in condition scoring (Broster and Broster, 1998). There was no significant difference in the error of prediction between the 3 groups (low, medium, and high) although the error of prediction increased from low to medium to high groups.

The comparison between predicted and observed condition score values for the Jersey data set with 3 parities is shown in Figure 7. The parameter set used initially was that shown in Table 2 but including the +0.3 adjustments made to $L^{\prime}$ and $L_{\text {next }}$ found to be beneficial from the comparison using the Holstein data set. As can be seen from Figure 7, the model provided a satisfactory fit to the observed data. The average error of prediction was 0.143 units of condition score (Table 4). In all 3 parities there was a tendency for the nadir of the predicted curve to be later than the nadir of the curve of observed condition scores. Consequently, the effect of reducing $T^{\prime}$ from its initial value of 112 DIM was examined. Lower errors of prediction (Table 4) and better fits (Figure 7) were obtained for all 3 parities by using a value of $T^{\prime}$ of $70 \mathrm{~d}$. However, the improvement was not a significant one.

The rates of lipid loss and gain calculated by the model for the 2 test data sets can be considered in terms of their effect on energy requirements. Rates of lipid loss and gain were converted to metabolizable energy equivalents by assuming that the effective energy yielded by $1 \mathrm{~kg}$ of lipid loss is $39.6 \mathrm{MJ}$, and the energy required for $1 \mathrm{~kg}$ of lipid gain is $56 \mathrm{MJ}$ (Emmans, 1994) together with an effective energy/metabolizable energy (ME) ration of 0.82 . In pregnancy, the maximum predicted rate of lipid gain was 0.192 and $0.145 \mathrm{~kg} / \mathrm{d}$ for Holsteins and Jerseys, respectively. This equates to an energy requirement of 13.1 and $9.9 \mathrm{MJ}$ of $\mathrm{ME} / \mathrm{d}$ for Holsteins and Jerseys, respectively. The model predicts the greatest rate of genetically driven lipid loss at the start of lactation $\left(\mathrm{dL}_{\text {calv }}\right)$. This was, on average, 0.943 and $0.875 \mathrm{~kg}$ of lipid loss $/ \mathrm{d}$. This equates to a change in energy requirement of -45.5 and $-42.2 \mathrm{MJ}$ of $\mathrm{ME} / \mathrm{d}$ for Holsteins and Jerseys, respectively. In the Holstein data set, there was a clear effect of calving condition score on energy requirements. The lipid mobilization of the cows with low condition score at calving (mean 3.04 ) reduced energy requirements by $14.6 \mathrm{MJ}$ of $\mathrm{ME} /$ d. The lipid mobilization of the cows with high condition score at calving (mean 4.37) reduced energy requirements by $75.2 \mathrm{MJ} \mathrm{ME} / \mathrm{d}$.

\section{DISCUSSION}

In this paper, a case has been made for considering that changes in body lipid reserves have a genetically driven component as well as an environmentally driven component. This view, derived from theoretical considerations, both evolutionary and physiological, fits with published evidence concerning the changes in body lipid through pregnancy and lactation.

Over 20 yr ago Bauman and Currie (1980) applied the concept of homeorhesis (Waddington, 1957; Kennedy, 1967) to lactation. The notion of "orchestrated or coordinated changes in metabolism of body tissues necessary to support a physiological state" (Bauman and Currie, 1980) was an important recognition of the fact that homeostasis alone cannot explain the dynamic associated with changing physiological state through pregnancy and lactation. However, the challenge of incorporating homeorhesis into the pre-existing (homeostasis based) view of lactational physiology, especially in quantitative terms, has all too frequently been avoided.

One possible reason for avoiding the idea of homeorhesis is that it requires a driving force or goal. The rationale presented in this paper suggests that the driving force is the expression of genotype through time to meet the evolutionary goal of maximizing reproductive success (see Friggens, 2003). The recognition that an orchestrated process implies a driving force has prompted alternative names for this process such as teleophoresis (see Chilliard et al., 2000; Bauman, 2000). In this paper, an attempt to describe teleophoresis as it affects body 

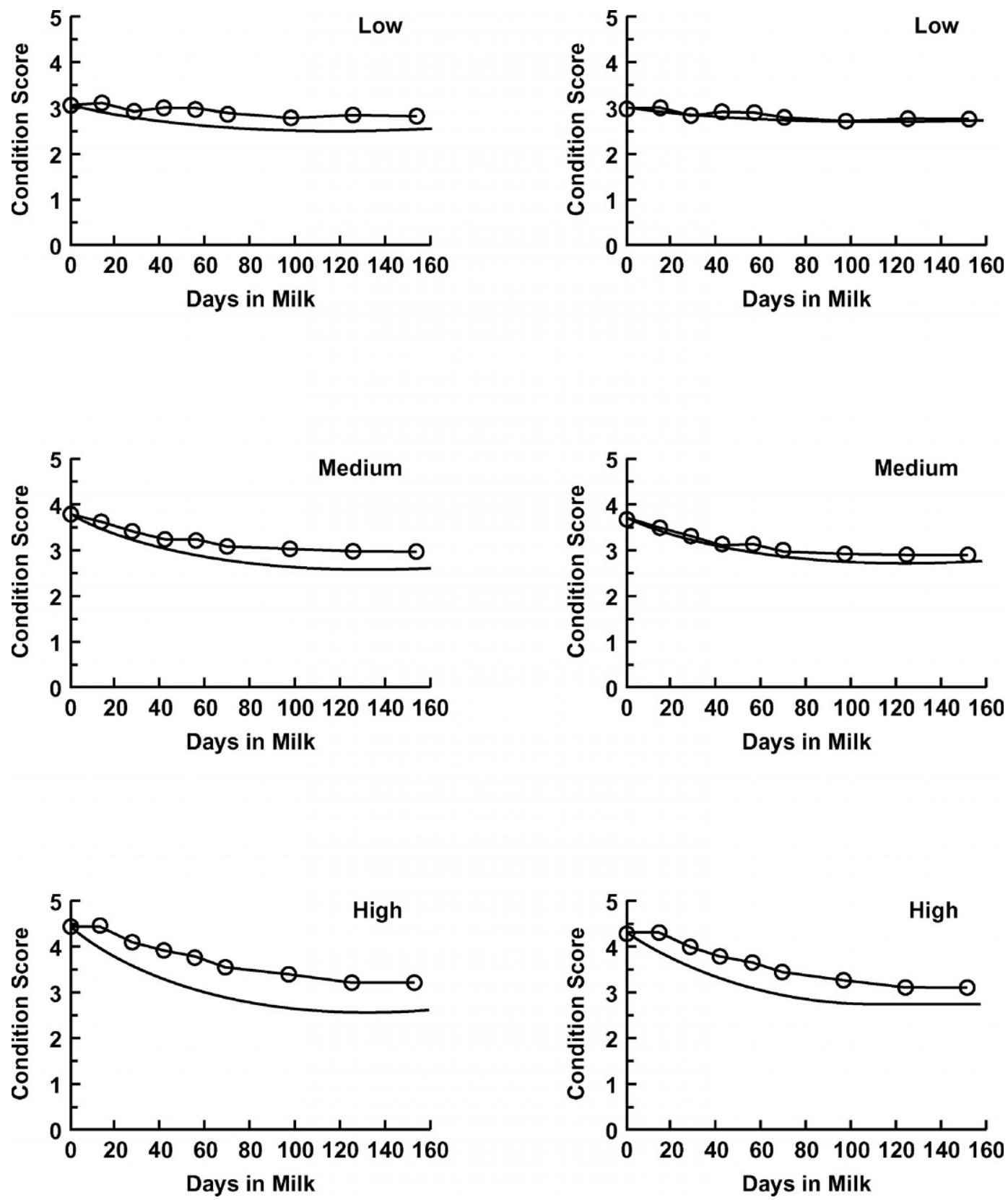

Figure 6. Comparison of observed (open circles) and predicted values of condition score relative to days in milk for Holstein cows with low, medium, or high levels of body condition at calving. The predicted values based on the initial parameter set (see Table 2) are shown in the left-hand set of graphs. The predicted values derived after increasing parameter values $\mathrm{L}^{\prime}$ and $\mathrm{L}_{\text {next }}$ by 0.3 are shown in the righthand set of graphs.

reserves has been made. This description is a high level description, it does not describe the metabolic and endocrine processes involved. There are 2 main reasons for this. The hormones that are involved in lipogenesis and lipolysis are important mediators of lipid metabolism, and thus lipid mobilization, but they are not the driving force behind lipid mobilization. In the context of an improved understanding of (dairy cow) physiology, study of the mediators such as the hormones addresses an important question; "how does lipid mobilization occur?" but it does not adequately address the question "why does lipid mobilization occur?" The other reason for choosing a high level description is that at this level there is sufficient information available to parameterize such a model for the practical purpose of improving prediction of energy requirements. 
Table 3. The error of prediction and percentage of the error due to bias on fitting the model to predict body lipid change to the Holstein data set with 3 different levels of condition score at calving.

\begin{tabular}{|c|c|c|c|}
\hline & \multicolumn{3}{|c|}{ Condition score at calving ${ }^{1}$} \\
\hline & Low & Medium & High \\
\hline \multicolumn{4}{|l|}{ Initial parameter set ${ }^{2}$} \\
\hline Error of prediction (condition score units) & 0.156 & 0.174 & 0.351 \\
\hline Bias $\%$ & 84 & 75 & 87 \\
\hline \multicolumn{4}{|l|}{ Adjusted parameter set ${ }^{3}$} \\
\hline Error of prediction (condition score units) & 0.051 & 0.066 & 0.236 \\
\hline Bias \% & 68 & 67 & 87 \\
\hline
\end{tabular}

\footnotetext{
${ }^{1}$ Average condition score at calving for low, medium, and high treatments was: $3.04,3.73$ and 4.37 , respectively.

${ }^{2}$ The initial parameter set is shown in Table 2.

${ }^{3}$ The parameter set was adjusted by increasing $\mathrm{L}^{\prime}$ to 0.29 and $\mathrm{L}_{\text {next }}$ to $0.35 \mathrm{~g}$ lipid/g empty body. This is equivalent to an increase of 0.25 condition score units.
}

The model presented here is a simple method for predicting the genetically driven changes in body lipid. The model describes both the predetermined genetically driven mobilization and genetically driven reconvergence when a cow is regaining her predetermined level of body fatness after a nutritional insult. The model was found to readily reproduce at least some observed patterns of change in body lipid reserves through lactation. The evaluation of the model used 2 data sets from 2 distinct breeds of dairy cattle, Holstein and Jersey. The average error of prediction was low, less than the variation normally associated with the recording of condition score (Broster and Broster, 1998), and was similar for the 2 data sets. Further, in one data set (Holstein) nutritional manipulation prior to calving had been used to create 3 different levels of body condition at calving (Figure 6). There was no significant difference between the 3 levels of calving condition score in the error of prediction of the condition score change after calving. Thus the model appears to adequately describe compensatory trajectories in body lipid.

In the Jersey data set, where cows from first, second, and third parities were represented (Figure 7), the model produced an adequate fit for all 3 parities. However, the error of prediction was greatest in parity 3 , which could possibly reflect a parity effect on the model parameter values, although this was the parity that also contained the fewest cows. The error of prediction for the 3 Jersey parities was improved, although not significantly, by decreasing $\mathrm{T}^{\prime}$ from the initial value of 112 to 70 DIM. No such adjustment was needed in the Holstein data set. Given that these results were derived from only 2 experiments with relatively few animals, any conclusions drawn from these data about breed, or genotype, differences in the values of the parameters of the model must be tentative. This is an issue warranting further study. If the model is to be used to produce improved predictions of energy requirements then it becomes important to quantify the extent to which the different parameters are affected by genotype and parity. The same applies to possible future genetic selection for body lipid usage (e.g., Coffey et al., 2001). In this context, the finding that the model readily reproduces observed patterns of change in body lipid reserves through lactation suggests that the model will provide the basis for a more biologically meaningful genetic evaluation of genetically driven body lipid mobilization.

It is relevant to discuss the limitations of the model presented here. The model is not designed to predict environmentally driven changes in body lipid. In this situation, by definition, the cow does not have sufficient nutritional resources available to allow the demands of both milk production and genetically driven changes in body lipid to be met. Predicting body mobilization when resources are limiting requires the development of rules to describe the partitioning of nutrients between "competing" functions. The large differences which can exist between individual animals in the way they partition nutrients has long been recognized (Kellner, 1926, p243). An adequate quantitative understanding of partition is still lacking (Bauman, 2000), and, therefore, this case is out with the scope of the present model. However, an important step towards generating such models is being able to describe the underlying genetically driven partition of nutrients between milk and body reserves (Ingvartsen et al., 1999). The model presented here provides a basis for achieving this.

Within the model presented, a central assumption is that the rate of change of body mobilization $(\mathrm{dL} / \mathrm{dt})$ changes in a linear way with days from calving. The assumption of linearity was made on the basis of choosing the simplest functional form that resulted in realistic patterns of changing body lipid reserves through lactation. We could find no strong evidence to justify adoption of a more complex function. The consequence of this assumption is that the patterns changing body 

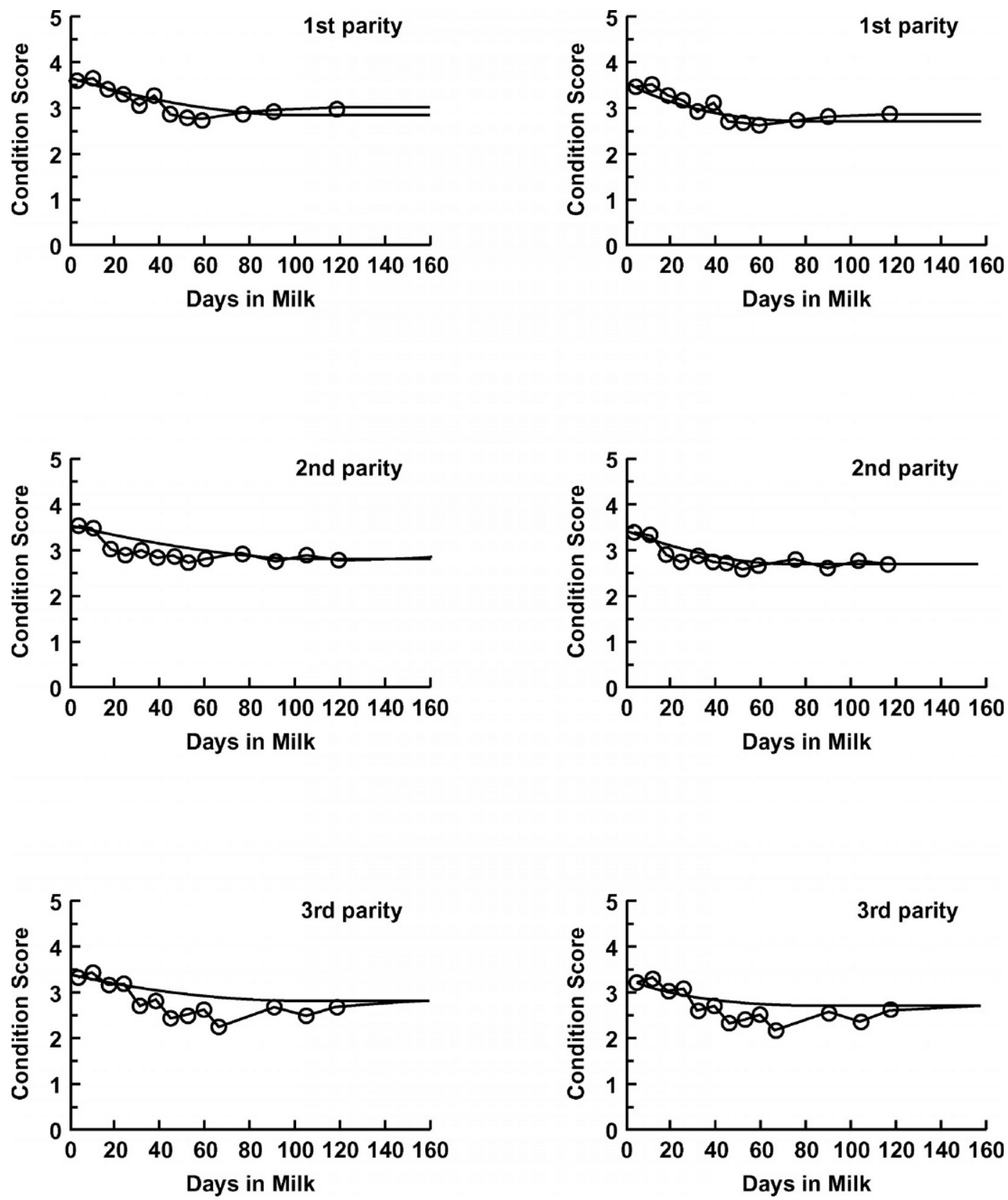

Figure 7. Comparison of observed (open circles) and predicted values of condition score relative to days in milk for Jersey cows in first, second, and third parities. The predicted values based on the adjusted parameter set (with $\mathrm{L}^{\prime}$ and $\mathrm{L}_{\text {next }}$ increased by 0.3 relative to the values in Table 2) are shown in the left hand set of graphs. The predicted values derived after changing the parameter values $\mathrm{T}^{\prime}$ to $70 \mathrm{DIM}$ are shown in the right hand set of graphs.

lipid reserves are described by quadratic functions. These functions appear to be adequate for practical purposes and have some attractive statistical properties. Estimates of genetic heritabilities and breeding values for condition score curves have recently become available (e.g., Pryce et al., 2000; Coffey et al., 2001; Koenen et al., 2001) and are, for similar reasons, all based on polynomial models of condition score relative to days from calving. However, it would be worthwhile to test the assumption of linearity with a purpose-built data set where the frequency and accuracy of body lipid measurements were sufficiently high as to allow a meaningful test of the assumption.

The underlying biological processes are, to some extent, taken into account in the current model by allowing for the effect of prior nutritional insult (as 
Table 4. The error of prediction and percentage of the error due to bias on fitting the model to predict body lipid change to the Jersey data set with 3 different parities.

\begin{tabular}{|c|c|c|c|}
\hline & \multicolumn{3}{|c|}{ Parity } \\
\hline & 1 & 2 & 3 \\
\hline \multicolumn{4}{|l|}{ Starting parameter set ${ }^{1}$} \\
\hline Error of prediction (condition score units) & 0.114 & 0.124 & 0.192 \\
\hline $\operatorname{Bias} \%$ & 4 & 11 & 31 \\
\hline \multicolumn{4}{|l|}{ Adjusted parameter set ${ }^{2}$} \\
\hline Error of prediction (condition score units) & 0.103 & 0.088 & 0.162 \\
\hline Bias \% & 37 & 0.1 & 22 \\
\hline
\end{tabular}

${ }^{1}$ The starting parameter set is the initial set of parameters (Table 2) adjusted by increasing $L^{\prime}$ and $L_{\text {next }}$ by 0.3 .

${ }^{2}$ The parameter set was adjusted by changing $\mathrm{T}^{\prime}$ to $70 \mathrm{DIM}$.

measured by $\mathrm{L}_{\text {calv }}$ ) on the trajectory of body lipid change. The model also makes the distinction between the body lipid change postcalving (up to $\mathrm{T}^{\prime}$ ) and body lipid change postconception. This is, however, a rather crude representation of physiological state. Although it is convenient to describe the changes in body lipid reserves as a function of time, this is unlikely to be the causal force behind changing body lipid reserves. The evolutionary arguments alluded to in the Rationale suggest that genetically driven changes in body lipid reserves should be described as a function of changing reproductive priority (Friggens, 2003). Clearly, this is an issue that should be addressed as it offers the opportunity to generalize the model to other mammals and to deal with different reproductive strategies. Further, we believe that the principles applied here to body reserves have the potential to improve our ability to quantify other teleophoretic processes.

\section{CONCLUSION}

The model presented here shows that it is possible to predict genetically driven curves of body lipid change through lactation using a model that requires few parameters and inputs that can be derived in practice. The assumptions on which the model is based were sufficient to predict changes in body lipid of both Holstein and Jersey cows under different nutritional conditions and parities. The extent to which the parameter values of the model are affected by genotype and parity remains to be tested. The model would provide the basis for biologically meaningful genetic evaluation of genetically driven body lipid mobilization.

\section{ACKNOWLEDGMENTS}

Aspects of this work were funded by the Danish Ministry of Food, Agriculture and Fisheries (projects GURSH-2, HUS97-2) and by the U. K. Ministry of Agricul- ture Fisheries and Food (Consortium DS04; RuminT project).

\section{REFERENCES}

Allden, W. G. 1970. The effects of nutritional deprivation on the subsequent productivity of sheep and cattle. Nutr. Abstr. Rev. 40:1167-1184.

Bauman, D. E. 2000. Ruminant Physiology: Digestion, Metabolism, Growth and Reproduction. P. B. Cronjé, ed. CAB International, Wallingford, UK.

Bauman, D. E., and W. B. Currie. 1980. Partitioning of nutrients during pregnancy and lactation: A review of mechanisms involving homeostasis and homeorhesis. J. Dairy Sci. 63:1514-1525.

Broster, W. H., and V. J. Broster. 1998. Body score of dairy cows. J. Dairy Res. 65:155-173.

Broster, W. H., V. J. Broster, and A. J. Clements. 1993. Feed utilization by the dairy cow over multiple lactations: A review. Livestock Prod. Sci. 34:1-21.

Chilliard, Y., A. Ferlay, L. Despres, and F. Bocquier. 1998. Plasma non esterified fatty acid response to a $\beta$-adrenergic challenge before or after feeding in energy underfed or overfed, dry or lactating cows. Anim. Sci. 67:213-223.

Chilliard, Y., A. Ferlay, Y. Faulconnier, M. Bonnet, J. Rouel, and F. Bocquier. 2000. Adipose tissue metabolism and its role in adaptations to undernutrition in ruminants. Proc. Nutr. Soc. 59:127134.

Coffey, M. P., G. C. Emmans, and S. Brotherstone. 2001. Genetic evaluation of dairy bulls for energy balance traits using random regression. Anim. Sci. 73:29-40.

Ehrhardt, R. A., R. M. Slepetis, A. W. Bell, and Y. R. Boisclair. 2001. Maternal leptin is elevated during pregnancy in sheep. Domest. Anim. Endocrinol. 21:85-96.

Emmans, G. C. 1988. Genetic components of potential and actual growth. Pages 153-181 in Animal Breeding Opportunities, BSAP Occasional Publication 12. British Society of Animal Production. Edinburgh, Scotland.

Emmans, G. C. 1994. Effective energy: A concept of energy utilization applied across species. Br. J. Nutr. 71:801-821.

Friggens, N. C. 2003. Body lipid reserves and the reproductive cycle: Towards a better understanding. Livestock Prod. Sci. 83:209-226.

Friggens, N. C., G. C. Emmans, I. Kyriazakis, J. D. Oldham, and M. Lewis. 1998. Feed intake relative to stage of lactation for dairy cows consuming total mixed diets with a high or low ration of concentrate to forage. J. Dairy Sci. 81:2228-2239.

Friggens, N. C., D. E. F. Hay, and J. D. Oldham. 1993. Interactions between major nutrients in the diet and the lactational performance of rats. Br. J. Nutr. 69:59-71.

Gagliostro, G., and Y. Chilliard. 1991a. Duodenal rapeseed oil infusion in early and midlactation cows. 4 . In vivo and in vitro adipose tissue lipolytic responses. J. Dairy Sci. 74:1830-1843. 
Gagliostro, G., and Y. Chilliard. 1991b. Duodenal rapeseed oil infusion in early and midlactation dairy cows. 2. Voluntary intake, milk production, and composition. J. Dairy Sci. 74:499-509.

Garnsworthy, P. C., and J. H. Topps. 1982. The effect of body condition of dairy cows at calving on their food intake and performance when given complete diets. Anim. Prod. 35:113-119.

Grummer, R. R., P. C. Hoffman, M. L. Luck, and S. J. Bertics. 1995. Effect of prepartum and postpartum dietary energy on growth and lactation of primiparous cows. J. Dairy Sci. 78:172-180.

Hammond, J. 1940. Farm animals - their breeding, growth, and inheritance. 1st ed. Edward Arnold \& Co., London, UK.

Ingvartsen, K. L., and Y. Boisclair. 2001. Leptin and the regulation of food intake, energy homeostasis and immunity with special focus on periparturient ruminants. Domest. Anim. Endocrinol. $21: 215-250$.

Ingvartsen, K. L., J. Foldager, O. Aaes, and P. H. Andersen. 1995. Effekt af fodeniveau i 24 uger før kælvning på foderoptagelse, produktion og stofskifte hos kvier og køer. I: Overgang til laktation. Malkekoens fodring og fysiologi under drægtighed og omkring kælvning. Forskningrapport 47 fra Statens Husdyrbrugsforsøg, 60-74. Frederiksberg, Denmark.

Ingvartsen, K. L., N. C. Friggens, and P. Faverdin. 1999. Food intake regulation in late pregnancy and early lactation. Pages 37-54 in Metabolic stress in dairy cows, BSAS Occasional Publication 24. British Society of Animal Science. Edinburgh, Scotland.

Kellner, O. 1926. The Scientific Feeding of Animals. 2nd ed. Duckworth, London, UK.

Kennedy, G. C. 1967. Pages 337-352 in Alimentary Canal Volume. 1. Control of Food and Water Intake. C. F. Code, ed. American Physiological Society, Washington, DC.

Knight, C. H. 2001. Lactation and gestation in dairy cows: Flexibility avoids nutritional extremes. Proc. Nutr. Soc. 60:527-537.

Koenen, E. P. C., R. F. Veerkamp, P. Dobbelaar, and G. De Jong. 2001. Genetic analysis of body condition score of lactating Dutch Holstein and Red-and-White heifers. J. Dairy Sci. 84:1265-1270.

Lowman, B. G., N. Scott, and S. Somerville. 1976. Condition scoring of cattle. Technical Bulletin 6,1-29. East of Scotland College of Agriculture. Edinburgh, Scotland.

McNamara, J. P. 1997. Adipose tissue metabolism during lactation: Where do we go from here? Proc. Nutr. Soc. 56:149-167.

Metz, S. H. M., and S. G. van den Bergh. 1977. Regulation of fat mobilization in adipose tissue of dairy cows in the period around parturition. Neth. J. Agric. Sci. 25:198-211.

Morrison, D. G., J. C. Spitzer, and J. L. Perkins. 1999. Influence of prepartum body condition score change on reproduction in multiparous beef cows calving in moderate body condition. J. Anim. Sci. 77:1048-1054.

Nielsen, H. M., N. C. Friggens, P. L. Løvendahl, J. Jensen, and K. L. Ingvartsen. 2003. The influence of breed, parity and stage of lactation on lactational performance and the relationship between body fatness and live weight. Livest. Prod. Sci. 79:119-133.

Oftedal, O. T. 2000. Use of maternal reserves as a lactation strategy in large mammals. Proc. Nutr. Soc. 59:99-106.

Pond, C. M. 1984. Pages 1-29 in Physiological Strategies in Lactation. M. Peaker, R. G. Vernon, and C. H. Knight, eds. The Zoological Society of London, London, UK.

Pryce, J. E., M. P. Coffey, and S. Brotherstone. 2000. The genetic relationship between calving interval, body condition score and linear type and management traits in registered holsteins. J. Dairy Sci. 83:2664-2671.

Pryce, J. E., M. P. Coffey, S. Brotherstone, and J. A. Woolliams. 2002. Genetic relationships between calving interval and body condition score conditional on milk yield. J. Dairy Sci. 85:1590-1595.

Theilgaard, P., N. C. Friggens, K. H. Sloth, and K. L. Ingvartsen. 2002. The effect of breed, parity and body fatness on the lipolytic response of dairy cows. Anim. Sci. 75:209-219.

Vernon, R. G., R. G. P. Denis, and A. Sørensen. 2001. Signals of adiposity. Domest. Anim. Endocrinol. 21:197-214.

Vernon, R. G., and D. J. Flint. 1984. Adipose tissue: Metabolic adaptation during lactation. Symp. Zool. Soc. Lond. 51:119-145.

Vernon, R. G., and C. M. Pond. 1997. Adaptations of maternal adipose tissue to lactation. J. Mammary Gland Biol. Neoplasia 2:231-241.

Waddington, C. H. 1957. The Strategy of the Genes. A Discussion of Some Aspects of Theoretical Biology. 1st ed. George Allen \& Unwin Ltd., London, UK.

Wright, I. A., and A. J. F. Russel. 1984. Estimation in vivo of the chemical composition of the bodies of mature cows. Anim. Prod. 38:33-44.

Wright, I. A., and A. J. F. Russel. 1991. Changes in the body composition of beef cattle during compensatory growth. Anim. Prod. 52:105-113.

Zerbini, E., A. G. Wold, and D. Demissie. 1996. Effect of draught force and diet on dry-matter intake, milk production and liveweight change in non-pregnant and pregnant cows. Anim. Sci. 62:225-233.

Zygoyiannis, D., C. Stamataris, N. C. Friggens, J. M. Doney, and G. C. Emmans. 1997. Estimation of the mature weight of three breeds of Greek sheep using condition scoring corrected for the effect of age. Anim. Sci. 64:147-153. 